destroys them. That it contains iodine, the following fact will prove:- When dissolved in water, and a stream of sulphuretted hydrogen is passed into it, it is decomposed, and iodine is set at liberty, which may be detected as usual by starch, or by the smell. In the course of these experiments, I noticed that iodine was perfectly soluble in sulphuric acid, with the assistance of heat, but again precipitated on the addition of water, circumstances which I do not remember eter seeing noticed in any work on chemistry. As I am wishful to resume my rescarches as soon as possible, and on a surer basis, I shall look with anxiety for your remarks. I remain, Sir,

Your obedient humble'servant, John S. HuLEx.

Elland, near Halifax, May, 1833.

* Mr. Hiley should repeat his experiment on a large scale, weigh accurately the product obtained, and note the time employed in procuring it. We have no doubt but that he will succeed. $\mathrm{He}$ has obviously gained the first point, that is, obtaining the acid.

\section{APPARATUS FOR PRODUCING FRICTION OR SHAMPOOING.}

\section{To the Editor of The LANCET.}

SiR,-I have for some time recommended an instrument, of which the following is a description, and as I am now convinced of its utility, in cases where friction (in any of its modifications, as shampooing, douch, \&c.) is an appropriate remedy, I think it of sufficient importance to give it publicity. From time to time, in the course of many years extensive opportunities in England and on the continent, I have, I believe, witnessed the employment of all the means that have been recommended for the purpose of assisting and re-animating torpid circulation, from the remedizm arenarum et ar undinum to Admiral Fenry's pomelling hammer, Dr. Gower's pulsator, and the still more recent plans of Dr. Balfour; but having found that these methods were either inefficient, or attended with inconvenience, $I$ was led to the construction of a percussor, which $I$ hope will be found as valuable an auxiliary by the profession generally, as I have uniformly found it to be.

Description.-Two balls of India rubher are affixed to the extremities of a circular whalebone rod, fifteen inches long. One of these balls admits the free egress and ingress of the air, and depends for its form upon its own elasticity, assisted by a small quantity of curled hair; the other is hermetically sealed, and its figure is preserved by the contained air. Upon the circular rod is a moveable handle, which regulates the length of the lever, and, consequently, the spring and stroke given by the instrument. By a slight movement of the hand, a rotatory motion is given to one of the balls, and it may thus be so applied, as to produce the effect of the gentlest friction, or be increased to that of the most powerful shampooing. If the compressible ball is placed a few minutes before the fire, it of course becomes more pliable and yielding, and, as the one hermetically sealed is always in a state of tension, the quality of the ictus may be modified at discretion. Leaving to the discrimination of the profession the cases in which this instrument may be employed with advantage,

I have the honour to be, Sir, Your obedient humble servant, J. P. Heath, M.D.

24, Craven Street, May 22, 1833.

P.S.-It is hardly necessary to observe that this simple instrument may be applied by an ordinary nurse, and in many cases by the patients themselves.*

rACCINATION.-POINTS AND GLASSES.

\section{To the Editor of The Lancet.}

SiR,-I am induced to trouble you on this occasion, in consequence of my impatience to set right the somewhat partial views of the author of the "Reasons for preserving Vaccine Lymph on Points instead of Glasses," which appeared in TrE LANCET for April 20th, and likewise from my anxious desire to place before the eyes of junior students, facts that I have established, which will, I trust, throw a degree of light upon the " modus operandi" of vaccinating by glasses. Although I have scrutinously perused and digested a whole host of authors upon the subject of vaccination and variola, I regret to say that I gained but little knowledge, except of the history of the one and the indications of the other.

* In a private note, which we see no objection to making public, our correspondent says, that " $\mathrm{Mr}$. Paul of Upper St. Martin's Lane, and Millusin of the $S$ trand, have nade the instu uments required by Dr. Heath's patients. Dr. Heath has, however, refrained from mentioning their names in his letter, presuming that any intelligent mechanic will be able to furnish so simple an apparatus; nevertheless, having witnessed several failuces (from in. attention to minute points), it is but justice to say that Paul has succeeded best. " $-E D$. L. 
I cannot concur in the recommendation of Mr. Perry, that glasses' should be entirely discarded from practice. On the contrary, I should insist upon the necessity of having glasses always at hand, for the reason of their being the best "preservative means" ever used for a fong keeping of vaccine lymph. If vac-! cinators persist in the absurd, and I should think, obsolete practice of dilating their lymph upon glass with fluid, by exhaling upon it, or holding it in the steam of tepid water, they must not expect it to be as invariable in its effects as that which is used pure and dry from a point. Is it, reasonable to expect a fine, prominent, and characteristic vesicle from the insertion of inpure lymph, i. e. lymph diluted with water? No more than to expect a child to thrive as well upon a diet of milkand-water as upon good rich milk. Even the most inconsiderate must see, that as the lymph is mixed with the blood, the blood of itself sufficiently dissolves the lymph when used dry from a glass, and that there is no necessity for dilution whaterer. But without farther extending these remarks, I will state a few facts, the result of extensice vaccination for the last three years. In the spring of 1831, I vaccinated a vast number of children, but failed, in the first attempt, in two in every five with glasses previously wetted by exhalation from the lungs. In 1832 I procured points, and was more successful; failure occurving in only one in every four. I was in the habit of making the blood flow, either by scratching, puncturing, or incision. I generally employed the three modes upon the arm of each person, and found incision the most successful. At the end of the spring of 1832 , I put up for keeping together six points and half a dozen glasses. Early in the spring of 1833, I used all the points and glasses in question in the same reek. The points all failed. Two of the glasses took beautifully, and the results supplied me with my entire expenditure of lymph during the remainder of the present season. Whichever way I operated, I was accustomed to draw blood plentifully. From the insertion of lymph through mere accident a most splendid vesicle arose. I took the hint, and have now laid it down as a rule never, scarcely, to make blood appear. Experience teaches me, that it is the most successful plan of any. Out of many scores that I have vaccinated this year (by means of glasses as well as points) only one failure occurred, which case has withstood six attempts at vaccination, and twice inoculation with variolous matter. For the success of this important though simple operation, I should wish to lay particular stress upon the practice of making but slight incisions. Because when blood is made to flow to the amount of a few drops, the lymph though inserted deeply is propelled outward by the blood, which, together with the lymph, forms a crust upon the orifice of the wound, and of course is generally rubbed off by the friction of the clothes, \&c.

Is it to be wondered that a person having the least to do with vaccination should hazard such an assertion as "that it is impossible to know when lymph upon glass is expended ?" It is needless to say, that the statement is without foundation, for it is not only porfectly visible to the sight, but quite perceptible to the touch with the lancet. I am, Sir, your obliged servant,

Dogelly, M. N. W., May 23rd, 1833.

Hegh OWex.

\section{COLLEGE OF PHYSICIANS.}

Monday, May $27 t h, 1833$.

"Grand performance!-For this night only! Theatre Micdical Royal, Pall Mall East.- Chief actor Sir Henry Halford.His Majesty's servant will this evening: enact, "Ancient Poisons, or Bx-gone Destris," a medical tragedy, adapted by permission of the celcbrated "Lempriere," with new views and decorations. The following royal, clerical, and legal figurantes will exhibit on this occasion:- His Royal Highness the, Duke of Sussex, his Grace the Primate of Ireland, the Lords Chief Baron Lyndhurst and Chief Justice Tindal, the Fice Chancellor, Justices Park, Bosanquet, Alderson, and Patterson, Barons Vaughan, Bolland, and Gurney.-To close with the popular farce of 'Milliver's Twist.'-Adinission by orders. Play to begin at 9 o'clock. Vivat Hemicus et Humbugga!"

Such are the heals of the Bill which, as Byron said of the Greel slave's ode, " might, or could, or wonld, or should have been," issued from the printing press of the London Theatre of Physicians, on Monday last, the 27th nitimo. The morning papers send their non-professional reporters to the monthly meetings of the College, just as they do to Drury. lane or Covant-garden, and next day we have notices of the performonces in the sanc column with the "Theatres" and "Public Exhibitions." Professional readers, who know what is the real character of the medico-dramatic spectacles in Pall Mall East, will not at any time expect us to bore them with the details of an essay 